\title{
Varenicline Reduces Context-Induced Relapse to Alcohol-Seeking through Actions in the Nucleus Accumbens
}

\author{
Franca Lacroix', Annie Pettorelli', Jean-Marie N Maddux², Atyeh Heidari-Jam' and Nadia Chaudhri*, \\ 'Center for Studies in Behavioral Neurobiology/FRQS Groupe de recherche en neurobiologie comportementale, CSBN/GRNC, Department of \\ Psychology, Concordia University, Montreal, QC, Canada; ${ }^{2}$ Department of Psychology, Lake Forest College, Lake Forest, IL, USA
}

\begin{abstract}
Varenicline, a pharmacotherapy for tobacco addiction, reduces alcohol consumption in humans and rodents. The therapeutic potential of varenicline would escalate if it also diminished conditioned responses elicited by alcohol-predictive cues, which can precipitate relapse in abstinent individuals. We investigated this application, along with the underlying neural substrates, using a robust preclinical assay in which relapse to alcohol-seeking was triggered by re-exposure to an alcohol-associated environmental context. Male, Long-Evans rats received Pavlovian conditioning sessions in which one auditory conditioned stimulus (CS+) was paired with 15\% ethanol and a second conditioned stimulus (CS - ) was not. Ethanol was delivered into a port for oral consumption and port entries triggered by each CS were recorded. Extinction was then conducted in a different context where the CS+ and CS - were presented without ethanol. To stimulate relapse, both cues were subsequently presented without ethanol in the prior conditioning context. Systemic varenicline $(0,0.5 \mathrm{or} 2.5 \mathrm{mg} / \mathrm{kg}$; intraperitoneal) blocked context-induced relapse to alcohol-seeking without affecting the ability to make a port entry. It also reduced context-induced relapse to sucrose-seeking, but only at the $2.5 \mathrm{mg} / \mathrm{kg}$ dose. Neuropharmacological studies showed that context-induced relapse to alcohol-seeking was attenuated by bilateral microinfusion of varenicline $(0.3 \mu \mathrm{l} / \mathrm{side}$ ) into the nucleus accumbens (NAc; 0 or $3.5 \mu \mathrm{g})$, but not the ventral tegmental area $(0,2$ or $4 \mu \mathrm{g})$. These data show for the first time that varenicline reduces relapse triggered by contexts that predict alcohol, and suggest that nicotinic acetylcholine receptors in the NAc are critical for this effect. Neuropsychopharmacology (2017) 42, 1037-1048; doi:I0.1038/npp.2016.254; published online 14 December 2016
\end{abstract}

\section{INTRODUCTION}

A burgeoning literature indicates that varenicline, a pharmacotherapy for smoking cessation, may hold promise as a new treatment for alcohol use disorder. Varenicline reduces alcohol use in heavy-drinking smokers (Fucito et al, 2011; McKee et al, 2009; Mitchell et al, 2012) and alcoholdependent individuals (de Bejczy et al, 2015; Litten et al, 2013). In rats, varenicline attenuates alcohol intake and operant alcohol-self administration, with either no effect on water intake and sucrose self-administration (Steensland et al, 2007) or an increase in the latter behavior (Wouda et al, 2011). These and related data (Le Foll et al, 2011; O'Connor et al, 2009) suggest that varenicline selectively dampens behaviors maintained by pharmacological, as opposed to non-drug reinforcers (Guillem and Peoples, 2010).

The therapeutic potential of varenicline would escalate if it also diminished reactivity to alcohol-predictive cues in abstinent individuals; however, this novel application has

\footnotetext{
*Correspondence: Dr N Chaudhri, Center for Studies in Behavioral Neurobiology/FRQS Groupe de recherche en neurobiologie comportementale, CSBN/GRNC, Department of Psychology, Concordia University, 714I Sherbrooke Street West, Room SP 244, Montreal, QC, Canada H4B-IR6, Tel: + I 5 I4 848 2424/22 I6,

E-mail: nadia.chaudhri@concordia.ca

Received 14 June 2016; revised 31 October 2016; accepted 2 November 2016; accepted article preview online II November 2016
}

received limited empirical attention. In humans, varenicline reduced alcohol craving and cue-elicited activation of the orbitofrontal cortex, with no effect on drinking behavior (Schacht et al, 2014). Varenicline dose-dependently attenuated cue-induced reinstatement of alcohol-seeking in rats (Funk et al, 2016; Wouda et al, 2011), congruent with doserelated reductions in cue-induced cocaine- (Guillem and Peoples, 2010) and nicotine-seeking (Le Foll et al, 2011, but see Wouda et al, 2011, and O'Connor et al, 2009). Moreover, varenicline reduced transient increases in oral alcohol intake produced by repeated bouts of abstinence from alcohol in mice (Sajja and Rahman, 2013). Thus, varenicline may diminish the relapse-inducing effects of alcohol-predictive cues on behavior.

In standard cue-induced reinstatement assays, operant responding is reinforced by drug delivery and a concurrent non-pharmacological stimulus. Following extinction where both the drug and nonpharmacological stimulus are withheld, reinstatement is triggered by response-contingent presentation of the nonpharmacological stimulus alone. Studies using this assay seldom ascertain that the nonpharmacological stimulus is devoid of intrinsic reinforcing properties that could either contribute to, or drive reinstatement (Caggiula et al, 2002). In addition, this assay does not enable the investigation of drug-seeking responses that are elicited in response to cues that have come to predict drug availability through Pavlovian learning processes, which can provoke 
drug-seeking and drug-taking behaviors that lead to relapse (Litt et al, 2000). Finally, a developing literature indicates that environmental contexts in which drugs are used can serve as powerful triggers for relapse (Bossert et al, 2004; Burattini et al, 2006; Chaudhri et al, 2008a,b; Crombag and Shaham, 2002; Janak and Chaudhri, 2010; Marinelli et al, 2007; Zironi et $\mathrm{al}, 2006)$ and the effects of varenicline on context-induced relapse are unknown. With these considerations in mind, the present studies tested the effects of varenicline on relapse using a robust, preclinical assay in which relapse was triggered by re-exposure to an alcohol-associated context. Dependent variables included entries into a fluid port where alcohol was delivered that were elicited by a conditioned stimulus that predicted alcohol, and port entries elicited by a different auditory stimulus that was never explicitly paired with alcohol. Control experiments examined the effect of varenicline on context-induced relapse to sucrose-seeking and on the expression of Pavlovian conditioned approach elicited by alcohol- and sucrose-predictive cues.

Varenicline binds to nicotinic acetylcholine receptors (nAChR), functioning as a potent, partial agonist at $\alpha 4 \beta 2$ nAChRs, a weak partial agonist at $\alpha 3 \beta 2$ and $\alpha 6 \mathrm{nAChRs,} \mathrm{a}$ weak agonist at $\alpha 3 \beta 4 \mathrm{nAChRs,}$ and a potent full agonist at $\alpha 7$ nAChRs (Grady et al, 2010; Mihalak et al, 2006). Interestingly, nAChRs may contribute to cue-driven alcohol-seeking. This hypothesis is suggested by a single study in which systemic infusion of mecamylamine, a non-selective $\mathrm{nAChR}$ antagonist, but not by dihydro- $\beta$-erythroidine $(\mathrm{DH} \beta \mathrm{E})$, an $\alpha 4 \beta 2 \mathrm{nAChR}$ antagonist, blocked the capacity of an alcoholpredictive, nonpharmacological stimulus to reinforce a novel operant response (Löf et al, 2007). This behavior was also abolished by microinfusion into the ventral tegmental area (VTA) of either mecamylamine or $\alpha$-conotoxin MII, a selective antagonist of $\alpha 3 \beta 2$ and $\alpha 6 \mathrm{nAChRs} \mathrm{(Löf} \mathrm{et} \mathrm{al,} \mathrm{2007).}$ Augmenting cholinergic tone within the VTA enhanced cueinduced relapse to heroin-seeking (Zhou et al, 2007), which is consistent with antagonist studies. Together, these data suggest that acetylcholine acting at $\alpha 3 \beta 2$ and $\alpha 6 \mathrm{nAChRs}$ within the VTA may mediate conditioned behavioral responding elicited by alcohol-predictive cues.

Alcohol-associated cues increase extracellular dopamine in the nucleus accumbens (NAc; Katner and Weiss, 1999; Löf et al, 2007) and intra-VTA mecamylamine, but not $\mathrm{Dh} \beta \mathrm{E}$, blocks this effect (Löf et al, 2007). Thus, cholinergic signaling in the VTA may mediate conditioned firing of dopamine neurons in response to alcohol-predictive cues. However, increases in NAc dopamine can also be caused by activation of nAChRs located presynaptically on dopamine terminals in the NAc (Champtiaux et al, 2003; Grady et al, 2002). There is little direct evidence that dopamine release through this mechanism, which is independent of the activity of VTA dopamine neurons, contributes to context-induced relapse of alcohol-seeking. However, this behavior does require functional activity in the NAc (Chaudhri et al, 2010), as well as dopamine D1-like receptors in the NAc (Chaudhri et al, 2009). Paradoxically, augmenting cholinergic tone in the NAc reduced cue-induced relapse to heroin-seeking (Zhou et al, 2007), although it is unclear whether this manipulation influenced presynpatic dopamine release.

There are no studies to date that have examined the impact of intra-VTA or intra-NAc varenicline on relapse to alcoholseeking. However, varenicline in the NAc but not VTA reduced voluntary alcohol consumption in rats, highlighting a role for nAChRs in the NAc in alcohol reinforcement (Feduccia et al, 2014). As the present studies found that systemic varenicline reduced context-induced relapse to alcohol-seeking, we examined the effect of intra-NAc or intra-VTA varenicline on this behavior to determine the neural loci of varenicline's effects.

\section{MATERIALS AND METHODS}

\section{Subjects}

Male, Long-Evans rats (Harlan, Indianapolis, IN, USA; 175-275 g on arrival) were single-housed in polycarbonate shoebox cages $(44.5 \mathrm{~cm} \times 25.8 \mathrm{~cm} \times 21.7 \mathrm{~cm})$ containing bedding (Sanichips, Harlan) on a $12 \mathrm{~h}$ light/dark cycle (lights on at $0700 \mathrm{~h}$ ) with humidity around $44 \%$. A nylabone (Nylabones, Bio-Serv) was provided in each cage. Rats had unrestricted access to food (Agribrands, Charles River) and water and were weighed and handled for 1 week before experiments commenced. All procedures were approved by the Concordia University Animal Research Ethics Committee and agree with recommendations from the Canadian Council on Animal Care.

\section{Apparatus}

Behavioral testing equipment is described in detail in the Supplementary Material.

\section{Drugs and Solutions}

Varenicline tartrate (Tocris, catalog number 3754) was dissolved in $0.9 \%$ sterile saline. Doses were based on the weight of the salt. A $15 \%$ ethanol solution $(v / v)$ was prepared by diluting a $95 \%$ ethanol solution in tap water and a $10 \%$ sucrose solution $(w / v)$ was prepared by dissolving sucrose in tap water.

\section{Home-Cage Ethanol Exposure}

Rats were acclimated to ethanol across 12 sessions of intermittent access to ethanol in the home-cage (Simms et al, 2008; Sparks et al, 2013; Wise, 1973). Procedural details and data can be found in Supplementary Figure S1.

\section{Surgery}

Standard stereotactic procedures (Chaudhri et al, 2013) were used to implant stainless steel guide cannulae (26 gauge, Plastics One, C315G) bilaterally into the VTA (AP - 5.80, $\mathrm{ML} \pm 2.70$ at a $14^{\circ}$ angle from vertical, DV -5.65) or NAc $\left(\mathrm{AP}+1.70, \mathrm{ML} \pm 2.85\right.$ at a $12^{\circ}$ angle from vertical, $\left.\mathrm{DV}-4.20\right)$ using coordinates from bregma. Microinfusion injectors were $3 \mathrm{~mm}$ longer than the guide cannulae. Surgery occurred after seven sessions of Pavlovian discrimination training (PDT) had been conducted (see details below).

\section{Intracranial Microinfusions}

Microinfusions $(0.3 \mu \mathrm{l}$ in $1 \mathrm{~min}, 2 \mathrm{~min}$ diffusion) were conducted in the behavior testing room using $33 \mathrm{~g}$ injectors 
(Plastics One, C315I) using standard procedures (Chaudhri et al, 2013). Rats were habituated to sham microinfusions conducted during PDT and extinction.

\section{Behavioral Procedures}

Habituation. Rats were transported to the behavior testing room in their home cages and left there for $20 \mathrm{~min}$. The next day they were weighed and handled in that same room. Twenty-four hours later, rats were weighed and then placed into a designated conditioning chamber for two $20 \mathrm{~min}$ sessions during which houselights were turned on, and port entries recorded. Chambers were set up as Context Type 1 and 2 consecutively, and the order of exposure to each context was counterbalanced such that half the rats were habituated to their PDT context first and half the rats were habituated to their extinction context first (see below).

Context Type 1 consisted of black cardboard covering the Plexiglas walls and ceiling of the conditioning chamber, a Plexiglas insert over the chamber floor, and a lemon odour sprayed into the waste tray beneath the chamber floor. Context Type 2 consisted of clear, transparent walls and ceiling, a perforated metal floor insert, and an almond odour.

Pavlovian discrimination training. During PDT sessions (58 min, 5-6 days per week), rats learned to discriminate between one conditioned stimulus (CS+) that was paired with an unconditioned stimulus (US), and a second conditioned stimulus $(\mathrm{CS}-$ ) that was presented without the US. The US was either ethanol or sucrose, as specified below.

Each rat was weighed and placed into a designated conditioning chamber. The computer program was started and $5 \mathrm{~min}$ later houselights were illuminated. The CS+ and CS - were each presented 16 times, according to separate variable-time $67 \mathrm{~s}$ schedules. Conditioned stimuli (10 s) consisted of a clicker $(2 \mathrm{~Hz}, 75-80 \mathrm{~dB})$ or a continuous white noise $(25 \mathrm{kHz}, 80-85 \mathrm{~dB})$. The US was delivered into the fluid port for oral consumption $4 \mathrm{~s}$ after the CS+ onset $(0.2 \mathrm{ml} / \mathrm{CS}+$ delivered over $6 \mathrm{~s}, 3.2 \mathrm{ml} /$ session $)$. Fluid ports were checked after each session, to ensure that the US had been consumed.

Half the conditioning chambers were set up as Context Type 1 and the remainder as Context Type 2. The context used for PDT was referred to as Context A. Designation of the white noise or clicker as the CS+ was counterbalanced across Context Type.

Extinction. Following PDT, extinction sessions were conducted in the Context Type that had not been experienced during PDT (Context B). The CS+ and CS - were presented as before but the US was not delivered (syringe pumps empty and turned off).

Relapse test. Twenty-four hours after the last extinction session, the capacity of the PDT context to trigger relapse was assessed. The test was identical to a PDT session in Context A in how the CS+ and CS - were presented. However, syringe pumps were turned off and US delivery was withheld.
Experiment 1a: Effect of Systemic Varenicline on Relapse to Alcohol- and Sucrose-Seeking

This study compared the effect of varenicline on contextinduced relapse to alcohol- and sucrose-seeking.

For Group $1(n=10)$ the US consisted of ethanol. These rats received exposure to ethanol in the home cage, as described in Supplementary Figure S1. For Group $2(n=14)$ the US consisted of sucrose. Half the rats in this group were exposed to ethanol in the home cage, while the remainder were exposed to water in place of ethanol. This manipulation allowed us to examine the impact of home-cage ethanol exposure on subsequent conditioning. We found no differences between ethanol and water-exposed rats in the acquisition or extinction of PDT (Supplementary Figure S2).

A within-subjects design was used to examine the impact of varenicline $(0,0.5$ or $2.5 \mathrm{mg} / \mathrm{kg} ; 1 \mathrm{ml} / \mathrm{kg}$; intraperitoneal; counterbalanced across tests) on context-induced relapse to alcohol-seeking (doses based on Wouda et al, 2011). Test 1 occurred after 19 PDT and 8 extinction sessions. Subsequent tests were separated by 4 PDT retraining sessions and 4 extinction sessions. Injections were administered in the colony room 20-30 min before the test. Rats were habituated to a saline injection before extinction session 6 and PDT retraining session 2 .

\section{Experiment 1b: Effect of Systemic Varenicline on PDT}

To determine whether varenicline affected the ability to make a port entry, we administered varenicline before a PDT session in which the CS+ was paired with the US.

Following the third relapse test, rats from Experiment 1a received eight $\mathrm{PDT}$ retraining sessions in Context $\mathrm{A}$. Varenicline (0 or $2.5 \mathrm{mg} / \mathrm{kg} ; 1 \mathrm{ml} / \mathrm{kg}$; intraperitoneal) was administered before PDT retraining sessions 4 and 8 using a counterbalanced, within-subjects design.

Data from two rats from Group 1 that failed to discriminate between the CS+ and CS - , and did not consume all the ethanol presented during PDT, were excluded from Experiment 1.

\section{Experiment 2: Effect of Intra-VTA Varenicline on Relapse to Alcohol-Seeking}

At 20-30 min before the relapse test in Context A, varenicline $(0,2$ or $4 \mu \mathrm{g} ; 0.3 \mu \mathrm{l} /$ hemisphere $)$ was bilaterally microinfused into the VTA using a counterbalanced, within-subjects design $(n=18$; doses based on Feduccia et al, 2014). Test 1 occurred after 18 PDT sessions in Context $\mathrm{A}$ and 8 extinction sessions in Context B. Subsequent tests were separated by three PDT retraining and eight extinction sessions.

\section{Experiment 3: Effect of Intra-NAc Varenicline on Relapse to Alcohol-Seeking}

At $20-30 \mathrm{~min}$ before the relapse test in Context A, varenicline ( 0 or $3.5 \mu \mathrm{g} ; 0.3 \mu \mathrm{l} /$ hemisphere) was bilaterally microinfused into the NAc using a counterbalanced, withinsubjects design ( $n=12$; doses based on Feduccia et al, 2014). Published data show that varenicline $(0.5,1$ or $2 \mu \mathrm{g} ; 0.5 \mu \mathrm{l} /$ hemisphere) in the NAc core-shell border, but not the NAc core or shell separately, reduced alcohol intake in the home 
cage (Feduccia et al, 2014). We tested a higher varenicline dose because pilot data showed that 1 and $3 \mu \mathrm{g}(0.3 \mu \mathrm{l} /$ hemisphere) doses in the NAc had only modest effects on port entry behavior.

The first relapse test occurred after 18 PDT sessions and 8 extinction sessions; however, response levels in test 1 were uncharacteristically low. Therefore, two subsequent tests were conducted that were identical to test 1 , except that midway during the $5 \mathrm{~min}$ delay before the onset of the houselight a $0.2 \mathrm{ml}$ drop of ethanol was delivered into the fluid port to optimize the relapse effect. Each test was separated by four PDT retraining and five extinction sessions and only data from tests 2 and 3 are reported.

We and others have shown previously that a $0.2 \mathrm{ml}$ drop of alcohol can boost relapse in an instrumental alcohol-seeking task (Chaudhri et al, 2008b; Wouda et al, 2011). This drop exposes rats to the sensory properties of alcohol (eg, taste and smell) and would not produce a pharmacological effect. To further assess the behavioral effects of this sensory prime, we examined the possibility that the $0.2 \mathrm{ml}$ drop of ethanol may have reinstated behavior independently of context. Following one PDT retraining session in Context A and two extinction sessions in Context $\mathrm{B}$, half of the rats received the $\mathrm{CS}+$ and CS - without ethanol in Context A, whereas the other half received both cues without ethanol in Context $\mathrm{B}$. Twenty-four hours later the test was repeated in the opposite context for each rat. A $0.2 \mathrm{ml}$ drop of ethanol was delivered into the port at the start of each test. We found a significant relapse to alcohol-seeking in Context A but not in Context B, confirming that the drop of ethanol did not provoke relapse outside the alcohol context (Supplementary Figure S3).

\section{Histology}

Standard light microscopy was used to examine injector tip placements in $50 \mu \mathrm{m}$ coronal sections that were stained with cresyl violet (Chaudhri et al, 2013). Five rats with VTA implants (Supplementary Figure S4) and four with NAc implants (Supplementary Figure S5) were excluded because of incorrect placements identified using the 1998 Paxinos and Watson rat brain atlas (Paxinos and Watson, 1998), or tissue damage.

\section{Statistical Analyses}

The number of port entries during a $10 \mathrm{~s}$ interval immediately before each CS+ and CS - was subtracted from the number of port entries during each corresponding CS, resulting in a normalized measure of port entries that accounted for differences in baseline responding. The number of port entries made during each CS+ trial at test was recorded. The number of non-CS port entries was calculated by subtracting port entries during the CS+ and CS - from the total number of port entries.

Relapse was assessed by comparing test data to an extinction baseline derived by averaging responding across the two extinction sessions immediately before the corresponding test. Relapse in saline-infused rats was assessed using planned, paired samples $t$-tests (Chaudhri et al, 2010) The effect of varenicline was assessed using repeatedmeasures ANOVA across the within-subjects factors of Dose (as per experiment) and CS. Significant Dose $\times$ CS interactions were pursued by targeted ANOVA, to examine the impact of Dose on responding during each CS. Where appropriate, post-hoc comparisons were conducted using Tukey's HSD to correct for multiple comparisons.

The significance level for all analyses was $p \leqslant 0.05$. The Greenhouse-Geisser correction was used whenever Mauchly's Test for Sphericity was significant. Analyses were run using SPSS (version 20.0).

\section{RESULTS}

In each experiment, port entries elicited by the CS+ increased across PDT sessions in Context A, whereas port entries during the CS - stabilized at a lower level. During extinction in Context B, CS+ port entries decreased across sessions (Supplementary Figure S6). In Experiment 1, overall levels of responding during PDT were significantly higher when the US was sucrose, compared with alcohol (Supplementary Figure S6). Consequently, data from these two groups were analyzed separately. As there was no impact of prior alcohol exposure on conditioning in rats that received sucrose as the US (Supplementary Figure S2) data from these two groups were combined for subsequent analyses.

\section{Experiment 1a: Effect of Systemic Varenicline on Relapse to Alcohol- and Sucrose-Seeking}

In saline-injected rats, re-exposure to the PDT context (Context A) following extinction in a different context (Context B) triggered a relapse in alcohol-seeking elicited by the CS+ (Figure 1a). Compared to extinction, there was a selective increase in port entries triggered by the CS+ $(t(7)=-3.61$, $p=0.009)$, but not the CS $-(t(7)=-0.09, p>0.05)$.

Systemic varenicline significantly attenuated contextinduced relapse to alcohol-seeking (Figure 1b: CS, $\mathrm{F}(1,7)=36.25, \quad p=0.001 ; \quad$ Dose $, \quad \mathrm{F}(2,14)=7.91, \quad p=0.019$; $\mathrm{CS} \times$ Dose, $\mathrm{F}(2,14)=9.51, p=0.002)$. Subsequent analyses on $\mathrm{CS}+$ port entries revealed a significant effect of Dose $(\mathrm{F}(2,14)=9.20, p=0.003)$, with no impact of varenicline on CS - port entries (Dose, $F(2,14)=0.24, \quad p>0.05$ ). Relative to saline, alcohol-seeking elicited by the CS+ was reduced by $0.5(p<0.05)$ and $2.5 \mathrm{mg} / \mathrm{kg}(p<0.05)$ of varenicline, with no difference between the two varenicline doses $(p>0.05)$.

To further examine the impact of varenicline we determined the number of port entries elicited by consecutive blocks of two $\mathrm{CS}+$ trials at test (Figure 1c). Alcohol-seeking triggered by the $\mathrm{CS}+$ decreased within test sessions, which occurred in the absence of alcohol delivery (Block, $\mathrm{F}(7,49)=7.23, p=0.004$ ). Varenicline reduced $\mathrm{CS}+$ port-entries (Dose, $\mathrm{F}(1,7)=14.78$, $p=0.023)$, without affecting the overall pattern of responding (Block $\times$ Dose, $\mathrm{F}(7,49)=0.89, p>0.05)$.

Saline-injected rats showed context-induced relapse to sucrose-seeking (Figure 1d). Compared with extinction, there was a selective increase in port entries triggered by the CS+ $(t(13)=-5.23, p<0.001)$, with no difference in $\mathrm{CS}-$ responding $(t(13)=-0.36, p>0.05)$.

Systemic varenicline reduced context-induced relapse to sucrose-seeking (Figure 1e), but only at the highest dose tested $(\mathrm{CS}, \mathrm{F}(1,13)=67.94, p<0.001$; Dose, $\mathrm{F}(2,26)=4.92$, $p=0.015 ; \mathrm{CS} \times$ Dose, $\mathrm{F}(2,26)=5.75, p=0.009)$. Subsequent analyses on $\mathrm{CS}+$ responding found a significant main effect of Dose $(\mathrm{F}(2,26)=5.63, p=0.009)$, with no impact of 
Effect of systemic varenicline on context-induced relapse to alcohol-seeking

a

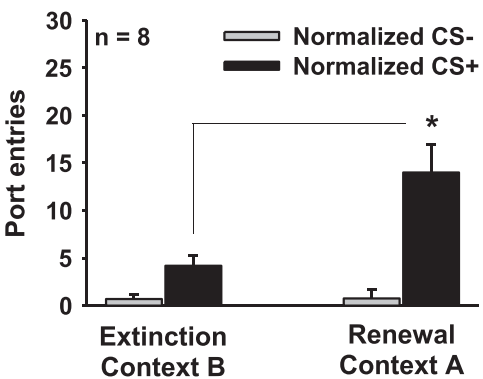

b Effect of varenicline on relapse

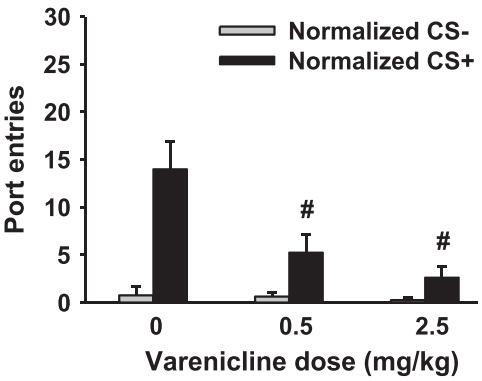

C Effect across CS+ trials

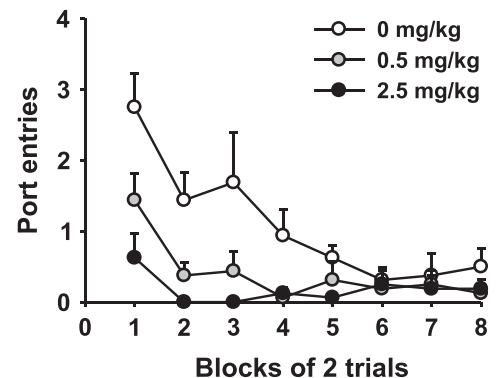

Effect of systemic varenicline on context-induced relapse to sucrose-seeking

d

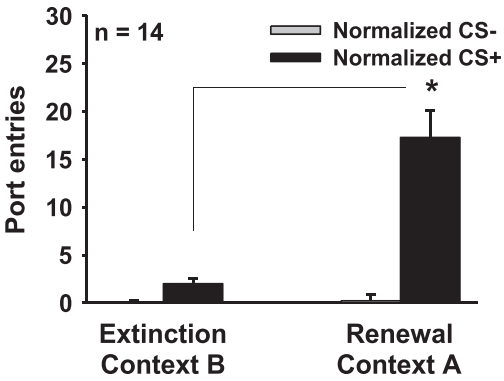

e Effect of varenicline on relapse

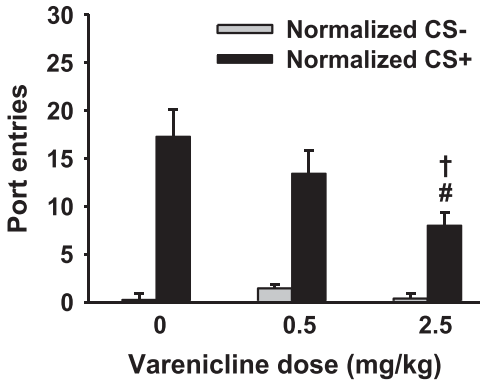

f

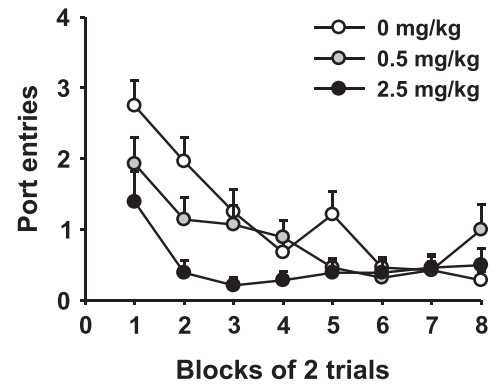

Figure I Varenicline reduced context-induced relapse to alcohol- and sucrose-seeking, with a lower dose being effective for relapse to alcohol-seeking. Relapse was triggered by placement into the Pavlovian discrimination training (PDT) context (Context A) following extinction in a different context (Context B). At test, the conditioned stimuli (CS+ and CS - ) were presented without alcohol or sucrose. (a) Mean ( \pm SEM) normalized port entries elicited by the CS - (grey bars) and CS+ (black bars) during extinction in Context B and the relapse (renewal) test in Context A for alcohol-trained rats that received saline at test. Here and in subsequent figures, normalized measures of responding were generated by subtracting port entries made during a I $0 \mathrm{~s}$ preCS interval from port entries made during each corresponding $10 \mathrm{~s}$ CS. Data from extinction represent a baseline obtained by averaging across the two extinction sessions before saline tests. (b) Mean ( \pm SEM) normalized CS - and CS+ port entries during relapse tests as a function of varenicline dose for alcohol-trained rats. (c) Mean ( \pm SEM) number of port entries averaged across blocks of two CS+ trials during relapse tests in alcohol-trained rats. At test, rats were administered 0 (white circles), 0.5 (grey circles) or $2.5 \mathrm{mg} / \mathrm{kg}$ (black circles) of varenicline. ( $\mathrm{d}-\mathrm{f}$ ) Identical measures as in (a-c) for rats that received sucrose during PDT. ${ }^{*} p<0.05$, Normalized CS+ at test significantly greater than extinction. ${ }^{\#} p<0.05$, Normalized CS+ significantly lower than $0 \mathrm{mg} / \mathrm{kg}$. ${ }^{\dagger} p<0.05$, Normalized CS+ significantly lower than $0.5 \mathrm{mg} / \mathrm{kg}$.

varenicline on $\mathrm{CS}-$ responding $(\mathrm{F}(2,26)=1.36, p>0.05)$. The $2.5 \mathrm{mg} / \mathrm{kg}$ dose of varenicline reduced CS+ port entries relative to saline $(p<0.01)$ and the $0.5 \mathrm{mg} / \mathrm{kg}$ dose $(p<0.05)$. Unlike with alcohol, $0.5 \mathrm{mg} / \mathrm{kg}$ of varenicline did not affect $\mathrm{CS}+$ port entries relative to saline $(\mathrm{p}>0.05)$.

Sucrose-seeking elicited by consecutive blocks of 2 CS+ trials (Figure 1f) decreased within test sessions (Block, $\mathrm{F}(7,91)=16.91, p<0.001)$. Varenicline reduced the overall level of sucrose-seeking elicited by the CS+ (Dose, $\mathrm{F}(2,26)=4.00, p=0.031)$, with a differential impact across $\mathrm{CS}+$ trials for different doses (Block $\times$ Dose, $\mathrm{F}(14,182)=2.43, p=0.004)$. To investigate this interaction, follow-up repeated-measures ANOVA were conducted to compare pairs of doses across blocks. There was a main effect of Block for each comparison (Saline $v s 0.5 \mathrm{mg} / \mathrm{kg}$, $\mathrm{F}(14,182)=2.43, \quad p=0.004 ; \quad$ Saline $\quad v s \quad 2.5 \mathrm{mg} / \mathrm{kg}$, $\mathrm{F}(7,91)=14.82, p<0.001 ; 0.5$ vs $2.5 \mathrm{mg} / \mathrm{kg}, \mathrm{F}(7,91)=7.48$, $p<0.001)$. There was a main effect of Dose when comparing saline and $2.5 \mathrm{mg} / \mathrm{kg}(\mathrm{F}(1,13)=9.41, p=0.009)$, but not when comparing $0.5 \mathrm{mg} / \mathrm{kg}$ with saline $(\mathrm{F}(1,13)=0.80, p>0.05)$ or $2.5 \mathrm{mg} / \mathrm{kg}(\mathrm{F}(1,13)=3.44, p=0.086)$. There was a Block $\times$
Dose interaction when comparing saline with $2.5 \mathrm{mg} / \mathrm{kg}$ $(\mathrm{F}(7,91)=3.28, p=0.027)$, but not when comparing $0.5 \mathrm{mg} /$ $\mathrm{kg}$ with saline $(\mathrm{F}(7,91)=2.80, p=0.057)$ or $2.5 \mathrm{mg} / \mathrm{kg}$ $(\mathrm{F}(7,91)=1.11, p>0.05)$. Follow-up paired samples $t$-tests found that port entries were significantly lower following $2.5 \mathrm{mg} / \mathrm{kg}$ of varenicline compared to saline in blocks 2 $(t(13)=3.49, p=0.004)$ and $3(t(13)=3.52, p=0.004)$.

Varenicline reduced port entries that occurred during non-CS intervals (Figure 2a and b). Repeated-measures ANOVA found a significant main effect of Dose in both alcohol$(\mathrm{F}(2,14)=8.75, p=0.014)$ and sucrose-trained $(\mathrm{F}(2,26)=7.20$, $p=0.003)$ rats. In alcohol-trained rats, compared with saline there was a significant reduction in non-CS responding following 2.5 $\mathrm{mg} / \mathrm{kg}(p<0.05)$. There was no difference in non-CS responding between saline and $0.5 \mathrm{mg} / \mathrm{kg}$ of varenicline $(p>0.05)$ or between both varenicline doses $(p>0.05)$. In sucrose-trained rats, compared with saline non-CS port entries were reduced following $2.5 \mathrm{mg} / \mathrm{kg}$ $(p<0.01)$, but not $0.5 \mathrm{mg} / \mathrm{kg}$ of varenicline $(p>0.05)$. Non-CS responding was also lower following $2.5 \mathrm{mg} / \mathrm{kg}$, compared to $0.5 \mathrm{mg} / \mathrm{kg}$ of varenicline $(p<0.05)$. 


\section{Effect of varenicline on Non-CS port entries}

a

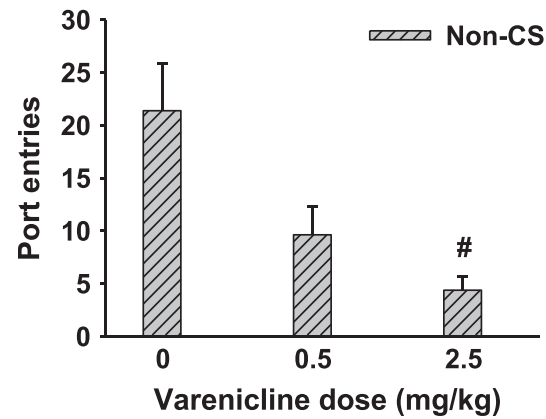

b

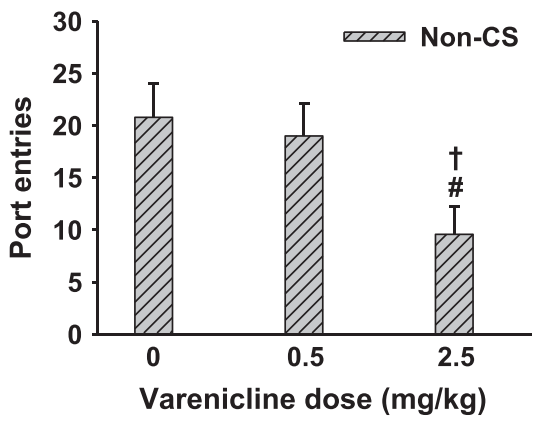

Figure 2 Systemic varenicline reduced the number of port entries made during intervals of the relapse test in Context A that did not include the CS+ and CS - (Non-CS). Data represent mean $( \pm$ SEM) non-CS port entries as a function of varenicline dose for (a) alcohol- and (b) sucrose-trained rats. ${ }^{\#} p<0.05$, significantly lower than $0 \mathrm{mg} / \mathrm{kg}$. ${ }^{\dagger} p<0.05$, significantly lower than $0.5 \mathrm{mg} / \mathrm{kg}$.

Effect of varenicline on Pavlovian discrimination training

a

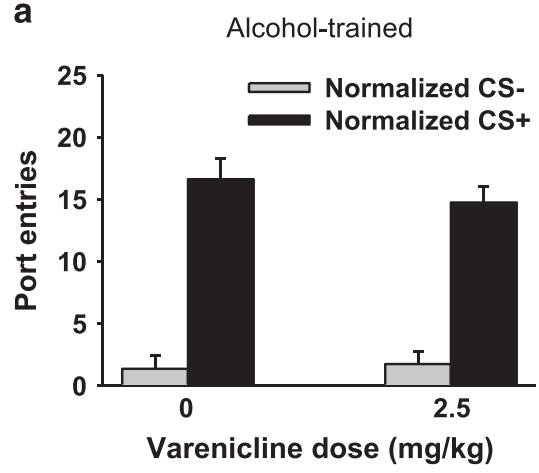

C

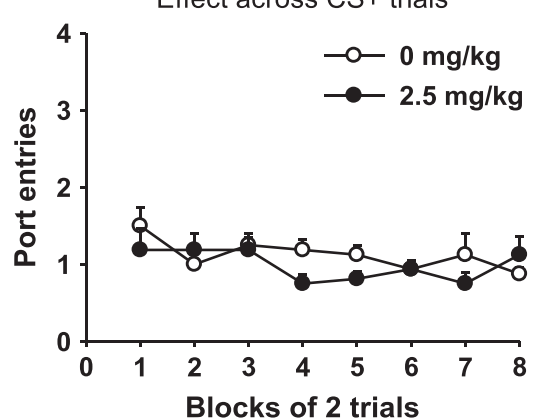

b

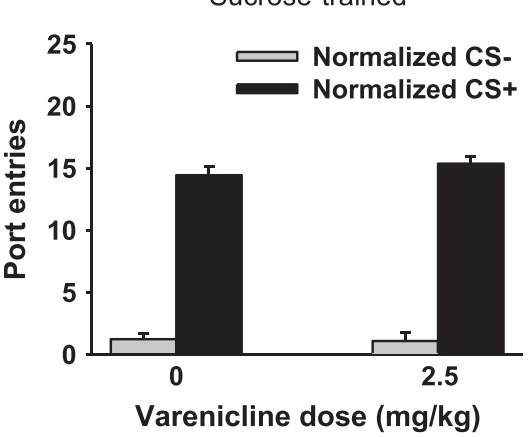

d

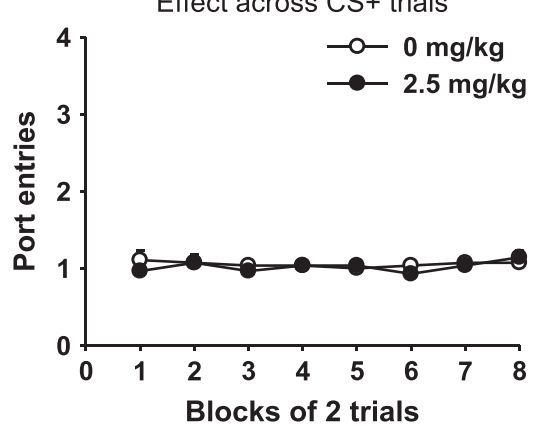

Figure 3 Varenicline did not affect port entries elicited by an alcohol- or sucrose-predictive CS+ during Pavlovian discrimination training (PDT). (a and b) Mean ( \pm SEM) normalized port entries elicited by the CS - (grey bars) and CS+ (black bars) as a function of varenicline dose in (a) alcohol- and (b) sucrose trained rats. (c and d) Mean ( \pm SEM) number of port entries averaged across blocks of two CS+ trials following systemic injection of 0 (white circles) or $2.5 \mathrm{mg} / \mathrm{kg}$ (black circles) of varenicline in (c) alcohol- and (d) sucrose-trained rats.

\section{Experiment 1b: Effect of Systemic Varenicline on PDT}

Varenicline did not impact port entries during PDT sessions in which the CS+ was paired with alcohol (Figure 3a) or sucrose (Figure $3 b$ ). In both cases, responding was higher during the CS + than the CS - (CS: alcohol, $\mathrm{F}(1,7)=90.56, p<0.001$; sucrose, $F$ $(1,13)=372.50, p<0.001$ ), with no main effects of Dose (alcohol, $F(1,7)=0.35, p>0.05$; sucrose, $F(1,13)=0.48, p>0.05)$, and no
$\mathrm{CS} \times$ Dose interactions (alcohol, $\mathrm{F}(1,7)=0.82, p>0.05$, sucrose: $F(1,13)=0.93, p>0.05)$. Port entries elicited by consecutive blocks of two CS+ trials at test (Figure $2 c$ and d) remained consistent within test sessions (Block: alcohol, $\mathrm{F}(7,49)=2.12$, $p=0.059$; sucrose, $\mathrm{F}(7,91)=0.69, p>0.05)$, with no impact of varenicline on behavior (Dose: alcohol, $\mathrm{F}(1,7)=1.08, p>0.05$; sucrose, $F(1,13)=0.60, \quad p>0.05 ;$ Block $\times$ Dose: alcohol, $F$ $(7,49)=1.62, p>0.05$; sucrose, $F(7,91)=0.57, p>0.05)$. 
Experiment 2: Effect of Varenicline in the VTA on Relapse to Alcohol-Seeking

Rats receiving intra-VTA saline showed context-induced relapse to alcohol-seeking (Figure 4a). Compared with extinction in Context $\mathrm{B}$, they made significantly more CS+ port entries at test in Context A $(t(12)=-4.25, p=0.001)$, with no difference across phase in CS - responding $(t(12)=0.00, p>0.05)$.

Intra-VTA varenicline did not impact relapse (Figure $4 \mathrm{~b}$ ). At test, more port entries were elicited by the CS+ than the CS - $(C S, F(1,12)=47.98, p<0.001)$, with no impact of varenicline on behavior (Dose, $\mathrm{F}(2,24)=0.44, p>0.05$; CS $\times$ Dose, $F(2,24)=0.294, p>0.05)$. There was no effect of

\section{Effect of intra-VTA varenicline on relapse to alcohol-seeking}

a

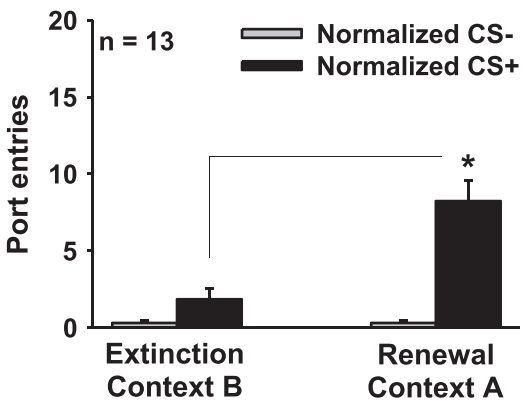

C

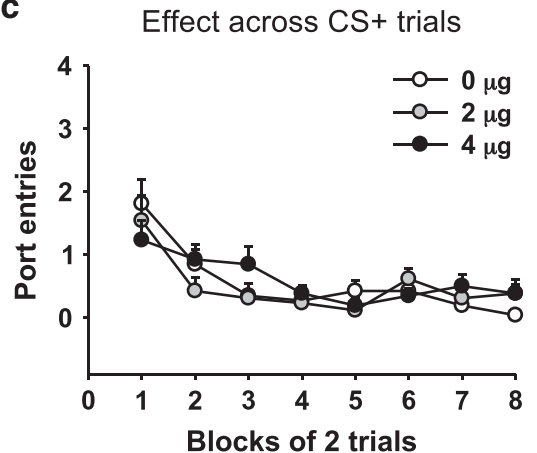

b

Effect of varenicline on relapse

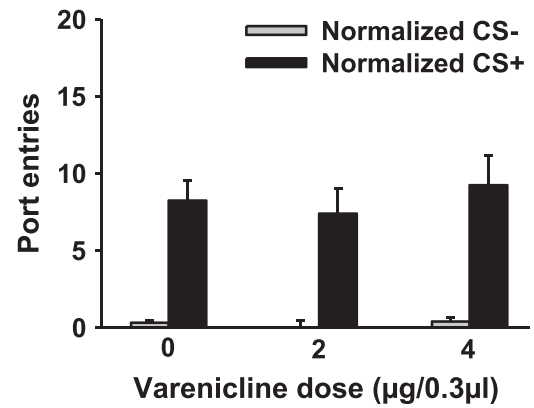

d

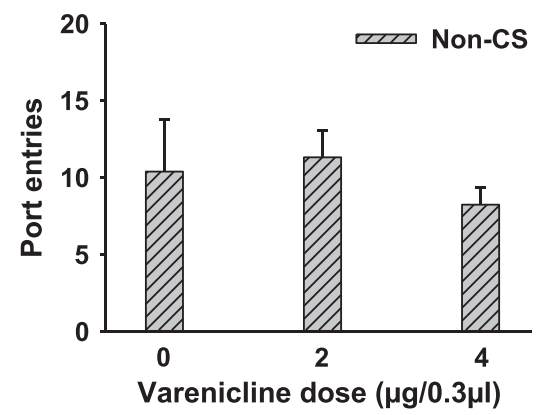

e

Placement of injector tips

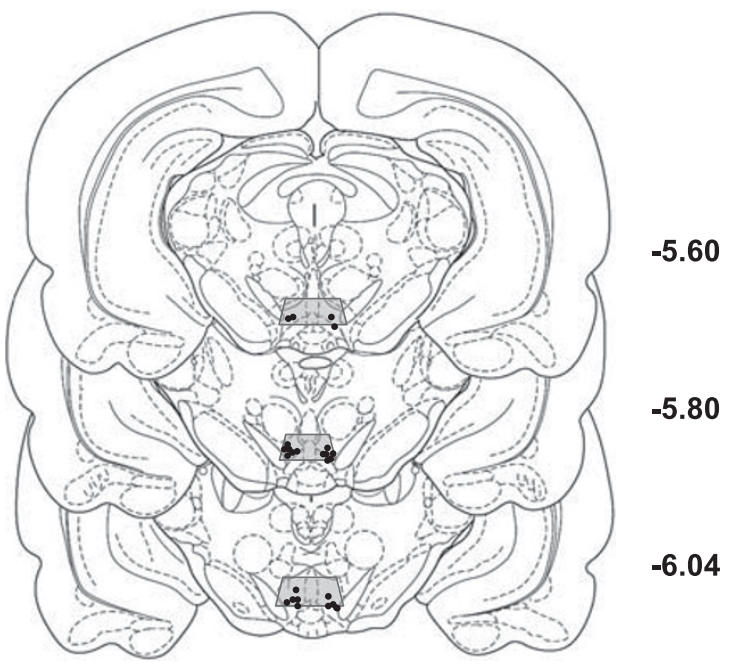

Figure 4 Varenicline microinfused into the ventral tegmental area (VTA) did not affect relapse to alcohol-seeking. (a) Mean ( \pm SEM) normalized port entries elicited by the CS - (grey bars) and CS+ (black bars) during extinction in Context B and the relapse (renewal) test in Context A in saline-infused rats. (b) Mean $( \pm$ SEM) normalized port entries during the CS - (grey bars) and CS+ (black bars) during relapse tests as a function of varenicline dose. (c) Mean $( \pm$ SEM) number of port entries across blocks of two CS + trials by rats microinfused with saline (white circles), $2 \mu \mathrm{g}$ (grey circles) or $4 \mu \mathrm{g}$ (black circles) of varenicline into the VTA at test. (d) Mean ( \pm SEM) port entries made during Non-CS intervals at test as a function of varenicline dose. (e) Representation of injector tips in the VTA. Placements within or on the border of the outlined area were considered to be accurate. Numbers indicate AP coordinates from bregma. Shaded area represents the VTA. $* p<0.05$. 
intra-VTA varenicline on the number of port entries across blocks of CS+ trials (Figure 4c; Block, $\mathrm{F}(7,84)=8.24$, $p=0.004 ;$ Dose, $\mathrm{F}(2,24)=0.34, p>0.05 ;$ Block $\times$ Dose, $F$ $(14,168)=1.28, \quad p>0.05)$, or on non-CS port entries (Figure $4 \mathrm{~d}$; Dose, $\mathrm{F}(2,24)=0.47, p>0.05)$. The placement of injector tips within the VTA is shown in Figure $4 \mathrm{e}$.

\section{Experiment 3: Effect of Varenicline in the NAc on Relapse to Alcohol-Seeking}

Rats receiving intra-NAc saline showed context-induced relapse to alcohol-seeking (Figure 5a). Compared with extinction in Context $\mathrm{B}$, they made significantly more CS+ port entries $(t(7)=-2.39, p=0.048)$ at test in Context $\mathrm{A}$, with no difference across phase in CS- port entries $(t(7)=-1.87, p>0.05)$.

Intra-NAc varenicline significantly attenuated relapse (Figure 5b: CS, $\mathrm{F}(1,7)=9.69, p=0.017$; Dose, $\mathrm{F}(1,7)=11.62$, $p=0.011 ; \mathrm{CS} \times$ Dose, $\mathrm{F}(1,7)=9.40, p=0.018)$. Paired samples $t$-tests confirmed that intra-NAc varenicline reduced port entries during the CS+ $(t(7)=3.40, p=0.011)$, with no impact on $C S-$ responding $(t(7)=1.78, p>0.05)$. The effect of varenicline was most pronounced near the beginning of the test session (Figure 5c). The number of port entries during blocks of CS+ trials decreased as a function of Block $(F(7,49)=6.90, p=0.007)$ and was lower following varenicline than saline (Dose, $F(1,7)=11.46, p=0.012$ ). A significant Block $\times$ Dose interaction $(F(7,49)=3.95, p=0.034)$ was found and follow-up paired samples $t$-tests indicated that varenicline significantly reduced the number of port entries in Blocks $1(t(7)=3.24, p=0.014), 2(t(7)=2.54$, $p=0.039)$ and $4(t(7)=3.42, p=0.011)$, relative to saline. Intra-NAc varenicline also reduced Non-CS port entries, relative to saline (Figure $5 \mathrm{~d} ; t(7)=3.06, p=0.018$ ). The placement of injector tips within the NAc is shown in Figure 5e.

To determine the effect of intra-NAc varenicline on general locomotor activity we examined latency (in seconds) to the first port at test. In this analysis 2 rats in the varenicline group that made zero port entries were assigned a maximum latency of $3480.95 \mathrm{~s}$, which represents the duration of the session. There was no significant difference in latency between saline (mean $\pm S E M=63.80 \pm 15.47)$ and varenicline $($ mean $\pm S E M=1093.66 \pm 548.84)$ tests $(t(7)=$ $-1.85, p>0.05)$.

\section{DISCUSSION}

Varenicline, a tobacco cessation product used in humans, reduced context-induced relapse to alcohol-seeking. At a high dose, systemically infused varenicline reduced relapse to alcohol- and sucrose-seeking, without affecting the capacity to make a port entry response. However, at a low dose, varenicline reduced relapse to alcohol- but not sucroseseeking. Although we anticipated that nAChRs in both the VTA and NAc would be implicated, only intra-NAc varenicline attenuated relapse to alcohol-seeking.

The finding that systemic administration of $2.5 \mathrm{mg} / \mathrm{kg}$ varenicline attenuated context-induced relapse to both alcohol- and sucrose-seeking appears to contradict evidence that similar varenicline doses $(2.0$ or $2.5 \mathrm{mg} / \mathrm{kg})$ reduce alcohol self-administration, with no impact on sucrose selfadministration (Steensland et al, 2007) or an increase in the latter behavior (Wouda et al, 2011). In our task, however, relapse was triggered by a return to the context in which alcohol or sucrose was previously consumed and neither alcohol nor sucrose was delivered at test. Thus, the present results suggest for the first time that cholinergic processes are part of a general mechanism that mediates context-induced relapse. This hypothesis is consistent with data showing that activation of $\mathrm{nAChRs}$ leads to increased drug-seeking in contexts associated with drug consumption (Cortright et al, 2012; Hall et al, 2010), suggesting that these receptors are involved in the mechanisms by which drug contexts elicit drug-seeking. If cholinergic activity is implicated in the retrieval of contextual associations, then varenicline may disrupt context-induced relapse by perturbing the interaction of endogenous acetylcholine at nAChRs.

Interestingly, $0.5 \mathrm{mg} / \mathrm{kg}$ of varenicline reduced contextinduced relapse to alcohol- but not sucrose-seeking. These results are consistent with findings that low doses of varenicline $(0.1$ and $0.3 \mathrm{mg} / \mathrm{kg})$ attenuated cue-induced reinstatement of cocaine-seeking, with no impact on cueinduced reinstatement of sucrose-seeking (Guillem and Peoples, 2010). The differential effect of low dose varenicline in the present research may be attributable to changes in $\mathrm{nAChR}$ expression levels, subunit composition, or affinity brought about by prolonged exposure to alcohol (Yoshida et al, 1982).

Varenicline did not affect conditioned responding elicited by the CS+ when it was paired with the US, suggesting that the reduction in port entries during relapse tests was not caused by a depressant effect on locomotor activity. Instead, our data suggest that cholinergic processes may be particularly important for conditioned responding that is maintained by the memory of a learned association between a CS and US. The lack of effect of varenicline on port entries when the CS+ was paired with alcohol provides an interesting contrast to studies in which varenicline reduced voluntary alcohol intake or operant alcohol self-administration (Steensland et al, 2007; Wouda et al, 2011). Unlike in the latter procedures, rats in the present studies did not control the timing of alcohol delivery or the volume of alcohol available per session, which could explain these differences. However, a broader range of varenicline doses should be tested to confirm a lack of effect of varenicline on the expression of Pavlovian conditioned alcohol-seeking.

Instrumental responding maintained by an alcoholassociated cue requires $\alpha 3 \beta 2$ and $\alpha 6$ nAChRs, but not $\alpha 4 \beta 2$ nAChRs in the VTA (Löf et al, 2007). Given that varenicline is a weak partial agonist at $\alpha 3 \beta 2$ and $\alpha 6 \mathrm{nAChRs}$ and that enhancing cholinergic tone within the VTA augments cue-induced relapse to heroin-seeking (Zhou et al, 2007), it was surprising that intra-VTA varenicline had no impact on context-induced relapse to alcohol-seeking. Because varenicline is also a potent partial agonist of $\alpha 4 \beta 2 \mathrm{nAChRs,} \mathrm{our}$ results corroborate the suggestion that $\alpha 4 \beta 2 \mathrm{nAChRs}$ in the VTA are not involved in cue-driven alcohol-seeking (Löf et al, 2007). Doses used in the present study (2 and $4 \mu \mathrm{g} / 0.3 \mu \mathrm{l} /$ hemisphere) were higher than those employed in an earlier report in which intra-VTA varenicline (1 and $2 \mu \mathrm{g} / 0.5 \mu \mathrm{l} /$ hemisphere) had no impact on oral alcohol intake (Feduccia et al, 2014). Future studies should test lower 
varenicline doses before ruling out the VTA as a neural target for the action of varenicline, as low varenicline doses sometimes produce effects that are not observed at high doses (Guillem and Peoples, 2010; Wouda et al, 2011). In addition, $\alpha$-conotoxin MII should be used to determine the involvement of $\alpha 3 \beta 2$ and $\alpha 6 \mathrm{nAChRs}$ in the VTA in

\section{Effect of intra-NAc varenicline on relapse to alcohol-seeking}

a

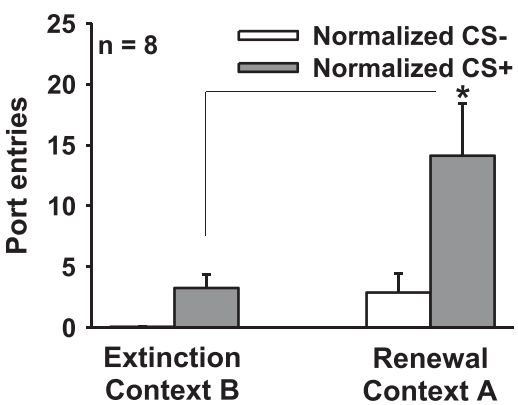

C

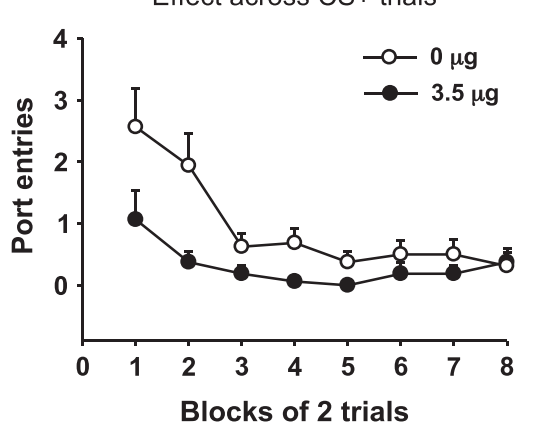

b

Effect of varenicline on relapse

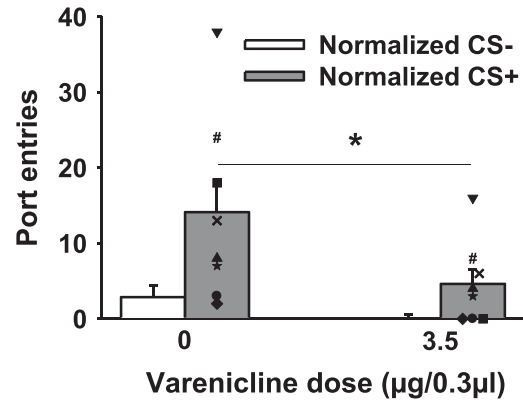

d

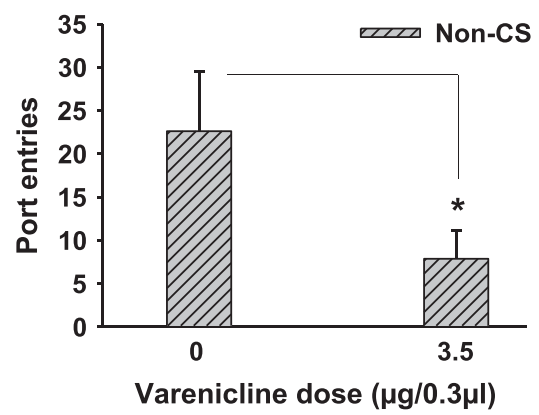

e

Placement of injector tips

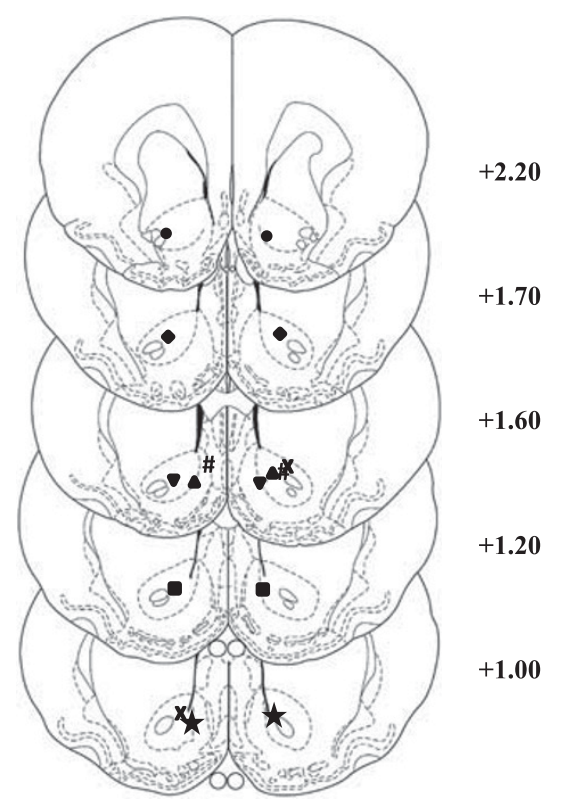

Figure 5 Varenicline in the nucleus accumbens (NAc) significantly attenuated context-induced relapse to alcohol-seeking. (a) Mean ( \pm SEM) normalized port entries during the CS - (white bars) and CS+ (grey bars) during extinction in Context B and the relapse (renewal) test in Context A in saline-infused rats. (b) Mean ( \pm SEM) normalized port entries during the CS - (white bars) and CS+ (grey bars) during relapse tests as a function of varenicline dose. Data from individual rats are represented using unique symbols (note the difference in $y$-axis scales in a and b). (c) Mean ( \pm SEM) number of port entries across blocks of two CS+ trials by rats microinfused with saline (white circles) or $3.5 \mathrm{\mu g}$ (black circles) of varenicline into the NAc. (d) Mean ( \pm SEM) port entries made during Non-CS intervals at test across varenicline dose. (e) Representation of injector tips in the NAc. Individuals rats are represented using the same unique symbols as in (b). Numbers indicate AP coordinates from bregma. $* 0<0.05$. 
context-induced relapse to alcohol-seeking. Finally, the anterior and posterior aspects of the VTA should be investigated separately, as the posterior but not anterior VTA has been implicated in the primary reinforcing properties of alcohol (Rodd-Henricks et al, 2000; Rodd et al, 2004) and a similar topographic gradient may exist for responding driven by alcohol cues.

Varenicline microinfused into the NAc reduced contextinduced relapse to alcohol-seeking, implicating ventral striatal nAChRs in this effect. Activation of cholinergic interneurons within the NAc elevates dopamine release (Cachope et al, 2012; Threlfell et al, 2012), suggesting that nAChRs located on terminals of VTA projections to the NAc (Grady et al, 2002) regulate striatal dopamine levels. Thus, placement into an alcohol-associated context following extinction in a different context may increase acetylcholine in the NAc, causing an augmentation of dopamine through the actions of acetylcholine at presynaptic nAChRs located on the terminals of dopaminergic neurons. Varenicline may disrupt this signaling process by binding to these nAChRs, thereby attenuating relapse. Additional research is needed to test this hypothesis, and to parse out the potentially distinct contributions of the NAc core, shell and core/shell border subregions in the reduction of context-induced relapse to alcohol-seeking by varenicline. Notably, each rat in the present study showed this reduction regardless of where the injector tips were located within the ventral striatum, suggesting that subregion may not be a consideration when evaluating the impact of varenicline on context-induced relapse to alcohol-seeking.

Both systemic and intra-NAc varenicline reduced port entries during periods of the session that excluded the CS+ and $\mathrm{CS}-$ (Non-CS), suggesting that nAChRs may mediate alcohol-seeking signalled directly by the alcohol-associated context, in addition to alcohol-seeking triggered by presentations of the CS+ in the alcohol-associated context. Because systemic varenicline did not impact port entries during PDT and intra-NAc varenicline had no impact on latency to the first port entry in the relapse test, this explanation outweighs a varenicline-induced decrease in general locomotor behavior.

In conclusion, our data reveal a novel effect of varenicline on relapse triggered by an alcohol-associated context, and identify the NAc as a brain region that is central to this effect. These findings extend reports that varenicline reduced alcohol intake in humans (de Bejczy et al, 2015; Fucito et al, 2011; Litten et al, 2013; McKee et al, 2009), decreased cue-induced relapse to alcohol-seeking in operant models (Funk et al, 2016; Wouda et al, 2011), and diminished transient elevations in alcohol intake produced by periods of deprivation from alcohol (Sajja and Rahman, 2013). The present data also suggest a new role for nAChRs in contextinduced relapse that extends to both pharmacological and non-drug reinforcers. They bolster the claim that carefully titrated doses of varenicline may help to maintain abstinence in individuals with alcohol use disorders (de Bejczy et al, 2015; Gowin et al, 2016; Litten et al, 2013; Soyka and Mutschler, 2015), and open a door for further exploration into the precise neural processes that underlie the impact of varenicline on alcohol intake and relapse.

\section{FUNDING AND DISCLOSURE}

The Natural Sciences and Engineering Research Council (387224-2010; NC) and a seed grant awarded by Concordia University (NC) funded this research. NC is the recipient of a Chercheur-Boursier Junior 2 award from Fonds de recherche du Québec - Santé, and a member of the Center for Studies in Behavioral Neurobiology/FRQS Groupe de recherche en neurobiologie comportementale. FL was supported by graduate fellowships from Concordia University and by Fonds de recherche du Québec - Santé, and by an NSERC undergraduate research award. The authors report no conflicts of interest.

\section{ACKNOWLEDGMENTS}

Experiments were designed by NC and conducted by FL, AP and J-MM. FL, AP, and J-MM analyzed the data. AHJ contributed to implementing Experiment 1 and trained FL. FL and NC wrote the manuscript, and all authors reviewed the manuscript and approved the final submission. We thank Steve Cabilio and David Munro for technical support and Dang-Vinh Chi Vo for conducting an experiment that was included in the original manuscript submission but removed in the revision due to space constraints.

\section{REFERENCES}

Bossert JM, Liu SY, Lu L, Shaham Y (2004). A role of ventral tegmental area glutamate in contextual cue-induced relapse to heroin seeking. J Neurosci 24: 10726-10730.

Burattini C, Gill TM, Aicardi G, Janak PH (2006). The ethanol selfadministration context as a reinstatement cue: acute effects of naltrexone. Neuroscience 139: 877-887.

Cachope R, Mateo Y, Mathur BN, Irving J, Wang H-L, Morales M et al (2012). Selective activation of cholinergic interneurons enhances accumbal phasic dopamine release: setting the tone for reward processing. Cell Rep 2: 33-41.

Caggiula AR, Donny EC, Chaudhri N, Perkins KA, Evans-Martin FF, Sved AF (2002). Importance of nonpharmacological factors in nicotine self-administration. Physiol Behav 77: 683-687.

Champtiaux N, Gotti C, Cordero-Erausquin M, David DJ, Przybylski C, Léna C et al (2003). Subunit composition of functional nicotinic receptors in dopaminergic neurons investigated with knock-out mice. J Neurosci 23: 7820-7829.

Chaudhri N, Sahuque L, Janak P (2008a). Context-induced relapse of conditioned behavioral responding to ethanol cues in rats. Biol Psychiatry 64: 203-210.

Chaudhri N, Sahuque LL, Cone JJ, Janak PH (2008b). Reinstated ethanol-seeking in rats is modulated by environmental context and requires the nucleus accumbens core. Eur J Neurosci 28: 2288-2298.

Chaudhri N, Sahuque LL, Janak PH (2009). Ethanol seeking triggered by environmental context is attenuated by blocking dopamine D1 receptors in the nucleus accumbens core and shell in rats. Psychopharmacology (Berl) 207: 303-314.

Chaudhri N, Sahuque LL, Schairer WW, Janak P (2010). Separable roles of the nucleus accumbens core and shell in contextand cue-induced alcohol-seeking. Neuropsychopharmacology 35: 783-791.

Chaudhri N, Woods CA, Sahuque LL, Gill TM, Janak PH (2013). Unilateral inactivation of the basolateral amygdala attenuates context-induced renewal of Pavlovian-conditioned alcohol-seeking. Eur J Neurosci 38: 2751-2761. 
Cortright JJ, Sampedro GR, Neugebauer NM, Vezina P (2012). Previous exposure to nicotine enhances the incentive motivational effects of amphetamine via nicotine-associated contextual stimuli. Neuropsychopharmacology 37: 2277-2284.

Crombag HS, Shaham Y (2002). Renewal of drug seeking by contextual cues after prolonged extinction in rats. Behav Neurosci 116: $169-173$.

de Bejczy A, Löf E, Walther L, Guterstam J, Hammarberg A, Asanovska G et al (2015). Varenicline for treatment of alcohol aependence: a randomized, placebo-controlled trial. Alcohol Clin Exp Res 39: 2189-2199.

Feduccia AA, Simms JA, Mill D, Yi HY, Bartlett SE (2014). Varenicline decreases ethanol intake and increases dopamine release via neuronal nicotinic acetylcholine receptors in the nucleus accumbens. $\mathrm{Br} J$ Pharmacol 171: $3420-3431$.

Fucito LM, Toll BA, Wu R, Romano DM, Tek E, O'Malley SS (2011). A preliminary investigation of varenicline for heavy drinking smokers. Psychopharmacology (Berl) 215: 655-663.

Funk D, Lo S, Coen K, Lê AD (2016). Effects of varenicline on operant self-administration of alcohol and/or nicotine in a rat model of co-abuse. Behav Brain Res 296: 157-162.

Gowin JL, Vatsalya V, Westman JG, Schwandt ML, Bartlett SE, Heilig M et al (2016). The effect of varenicline on the neural processing of fearful faces and the subjective effects of alcohol in heavy drinkers. Alcohol Clin Exp Res 40: 979-987.

Grady SR, Drenan RM, Breining SR, Yohannes D, Wageman CR, Fedorov NB et al (2010). Structural differences determine the relative selectivity of nicotinic compounds for native $\alpha 4 \beta 2^{*}$-, $\alpha 6 \beta 2^{\star}$-, $\alpha 3 \beta 4^{*}$ - and $\alpha 7$-nicotine acetylcholine receptors. Neuropharmacology 58: 1054-1066.

Grady SR, Murphy KL, Cao J, Marks MJ, McIntosh M, Collins AC (2002). Characterization of nicotinic agonist-induced [3H]dopamine release from synaptosomes prepared from four mouse brain regions. J Pharmacol Exp Ther 301: 651-660.

Guillem K, Peoples LL (2010). Varenicline effects on cocaine self administration and reinstatement behavior. Behav Pharmacol 21: 96-103.

Hall BJ, Pearson LS, Buccafusco JJ (2010). Effect of administration of the nicotinic acetylcholine receptor antagonist BTMPS, during nicotine self-administration, on lever responding induced by context long after withdrawal. Neuropharmacology 58: 429-435.

Janak PH, Chaudhri N (2010). The potent effect of environmental context on relapse to alcohol-seeking after extinction. Open Addict J 3: 76-87.

Katner SN, Weiss F (1999). Ethanol-associated olfactory stimuli reinstate ethanol-seeking behavior after extinction and modify extracellular dopamine levels in the nucleus accumbens. Alcohol Clin Exp Res 23: 1751-1760.

Le Foll B, Chakraborty-Chatterjee M, Lev-Ran S, Barnes C, Pushparaj A, Gamaleddin I et al (2011). Varenicline decreases nicotine self-administration and cue-induced reinstatement of nicotine-seeking behaviour in rats when a long pretreatment time is used. Int J Neuropsychopharmacol 15: 1265-1274.

Litt MD, Cooney NL, Morse P (2000). Reactivity to alcohol-related stimuli in the laboratory and in the field: predictors of craving in treated alcoholics. Addiction 95: 889-900.

Litten RZ, Ryan ML, Fertig JB, Falk DE, Johnson B, Dunn KE et al (2013). A double-blind, placebo-controlled trial assessing the efficacy of varenicline tartrate for alcohol dependence. J Addict Med 7: 277-286.

Löf E, Olausson P, deBejczy A, Stomberg R, McIntosh JM, Taylor JR et al (2007). Nicotinic acetylcholine receptors in the ventral tegmental area mediate the dopamine activating and reinforcing properties of ethanol cues. Psychopharmacology (Berl) 195: 333-343.

Marinelli PW, Funk D, Juzytsch W, Li Z, Lê AD (2007). Effects of opioid receptor blockade on the renewal of alcohol seeking induced by context: relationship to c-fos mRNA expression. Eur J Neurosci 26: 2815-2823.

McKee SA, Harrison ELR, O’Malley SS, Krishnan-Sarin S, Shi J, Tetrault JM et al (2009). Varenicline reduces alcohol selfadministration in heavy-drinking smokers. Biol Psychiatry 66: 185-190.

Mihalak KB, Carroll FI, Luetje CW (2006). Varenicline is a partial agonist at $\alpha 4 \beta 2$ and a full agonist at $\alpha 7$ neuronal nicotinic receptors. Mol Pharmacol 70: 801-805.

Mitchell JM, Teague CH, Kayser AS, Bartlett SE, Fields HL (2012). Varenicline decreases alcohol consumption in heavy-drinking smokers. Psychopharmacology 223: 299-306.

O'Connor EC, Parker D, Rollema H, Mead AN (2009). The $\alpha 4 \beta 2$ nicotinic acetylcholine-receptor partial agonist varenicline inhibits both nicotine self-administration following repeated dosing and reinstatement of nicotine seeking in rats. Psychopharmacology 208: 365-376.

Paxinos G, Watson C (1998). The Rat Brain in Stereotaxic Coordinates. Academic Press: San Diego.

Rodd ZA, Melendez RL, Bell RL, Kuc KA, Zhang Y, Murphy JM et al (2004). Intracranial self-administration of ethanol within the ventral tegmental area of male Wistar rats: evidence for involvement of dopamine neurons. J Neurosci 24: 1050-1057.

Rodd-Henricks ZA, McKinzie DL, Crile RS, Murphy JM, McBride WJ (2000). Regional heterogeneity for the intracranial self-administration of ethanol within the ventral tegmental area of female Wistar rats. Psychopharmacology (Berl) 149: 217-224.

Sajja RK, Rahman S (2013). Nicotinic receptor partial agonists modulate alcohol deprivation effect in C57BL/6J mice. Pharmacol Biochem Behav 110: 161-167.

Schacht J, Anton RF, RAndall PK, Li X, Henderson S, Myrick H (2014). Varenicline effects on drinking, craving and neural reward processing among non-treatment-seeking alcohol-dependent individuals. Psychopharmacology 231: 3799-3807.

Simms JA, Steensland P, Medina B, Abernathy KE, Chandler LJ, Wise $\mathrm{R}$ et al (2008). Intermittent access to $20 \%$ ethanol induces high ethanol consumption in Long-Evans and Wistar rats. Alcohol Clin Exp Res 32: 1816-1823.

Soyka M, Mutschler J (2015). Treatment-refractory substance use disorder: focus on alcohol, opioids, and cocaine. Prog Neuropsychopharmacol Biol Psychiatry 70: 148-161.

Sparks LM, Sciascia JM, Ayorech Z, Chaudhri N (2013). Vendor differences in alcohol consumption and the contribution of dopamine receptors to Pavlovian-conditioned alcohol-seeking in Long-Evans rats. Psychopharmacology 231: 753-764.

Steensland P, Simms JA, Holgate JK, Richards J, Bartlett SE (2007). Varenicline, an $\alpha 4 \beta 2$ nicotinic acetylcholine receptor partial agonist, selectively decreases ethanol consumption and seeking. Proc Natl Acad Sci USA 104: 12518-12523.

Threlfell S, Lalic T, Platt NJ, Jennings KA, Deisseroth K, Cragg SJ (2012). Striatal dopamine release is triggered by synchronized activity in cholinergic interneurons. Neuron 75: 58-64.

Wise RA (1973). Voluntary ethanol intake in rats following exposure to ethanol on various schedules. Psychopharmacologia 29: 203-210.

Wouda JA, Riga D, De Vries W, Stegeman M, van Mourik Y, Schetters D et al (2011). Varenicline attenuates cue-induced relapse to alcohol, but not nicotine seeking, while reducing inhibitory response control. Psychopharmacology (Berl) 216: 267-277. 
Yoshida K, Engel J, Liljequist S (1982). The effect of chronic ethanol administration on high affinity3H-nicotinic binding in rat brain. Naunyn Schmiedeberg Arch Pharmacol 321: 74-76.

Zhou W, Liu H, Zhang F, Tang S, Zhu H, Lai M et al (2007). Role of acetylcholine transmission in nucleus accumbens and ventral

tegmental area in heroin-seeking induced by conditioned cues. Neuroscience 144: 1209-1218.

Zironi I, Burattini C, Aicardi G, Janak PH (2006). Context is a trigger for relapse to alcohol. Behav Brain Res 167: 150-155.

Supplementary Information accompanies the paper on the Neuropsychopharmacology website (http://www.nature.com/npp) 